\title{
Intention to move in renovated historical blocks in China
}

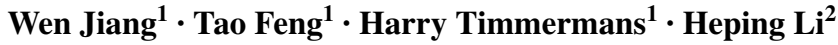

Received: 5 August 2017 / Accepted: 4 May 2018 / Published online: 10 May 2018

(C) The Author(s) 2018

\begin{abstract}
Using data from 8 renovated historical blocks in China, the influence of socialdemographic characteristics and residential satisfaction on the intention to move is analysed using multinomial logit models. To explore the observed and unobserved heterogeneity among individuals, a mixed logit model was adopted. The model results indicate that older residents and residents who live in blocks during the middle renovation stage are less interested in relocating. Higher residential satisfaction will lead to a lower intention to move house, and housing satisfaction and satisfaction with the living environment have a higher impact compared with satisfaction related to other residential dimensions. Moreover, the interaction between neighbourhood satisfaction and renovation stages was found influential, while the unobserved taste variation between residents was not identified.
\end{abstract}

Keywords Intention to move $\cdot$ Residential satisfaction $\cdot$ Heterogeneity $\cdot$ Renovated historical block · China

\section{Introduction}

Most adults will or have experienced a residential move at least once in their lifetime. From a behavioural perspective, residential mobility consists of three stages: intention to move, the selection of the dwelling and location, and the real move (Speare et al. 1975). The intention to move refers to the first phase of the residential mobility process in which an individual or household develops the idea to relocate. It triggers a process of latent or actual exploring the housing market and searching for a house. Depending on the urgency of moving and the ease of finding a house that satisfies the needs and aspirations of the

Tao Feng

t.feng@tue.nl

1 Urban Planning Group, Eindhoven University of Technology, PO Box 513, Den Dolech 2, 5600 MB Eindhoven, The Netherlands

2 Chongqing University, Chongqing, China 
individual or household, this search process may take a long time. If the search is successful, the intention to move is translated into the selection of a new housing, with a particular profile located in somewhere space. Conversely, if too much effort has been spent unsuccessfully, the intention to move house may gradually disappear. Once the new house has been selected, it is followed by the actual move, in which households physically move from their old to the newly selected house.

Considering the importance of residential mobility in people's life, finding determinants of residential mobility has attracted lots of attentions in residential field. Different residential attributes (such as housing, neighbourhood and accessibility attributes) have been examined as the determinants of residential mobility (e.g., Clark and Coulter 2015; Ren and Folmer 2017). Life cycle events are also analysed how they impact residential mobility (e.g., Courgeau 1985; Rabe and Taylor 2010). Residential satisfaction is another popular determinant to be examined for its influence on residential mobility (e.g., Diaz-Serrano and Stoyanova 2010; Kwon and Beamish 2013; Kim et al. 2015). In all these research, very limited amount of studies have considered the difference between residents during the decision making process in residential mobility. Individuals are simply assumed to think and behave homogeneously. However, due to the distinct personal and household characteristics, individuals may have different requirements about housing and express different moving intention.

Furthermore, studies examining the determinants of residential mobility in renovated historical blocks in China is extremely scarce, which is surprising considering the importance of this topic. These blocks are of great theoretical and applied interest because on the one hand residents living there are encountering various constraints. For instance, the worse housing condition (e.g., poor technical quality and lack of infrastructure) and lower percentage of house ownership. On the other hand, residents in historical blocks are facing many opportunities. These blocks generally have better public transportation and higher house price as they are located in the centre of cities. Neighbourhood bounding is also stronger in historical blocks. From the policy perspective, as improving housing conditions to provide a better living environment in historical blocks has always been one of the goals of local government, all these blocks have gone through different stages of renovations. During the renovation process, governments provide repair support to houses (e.g., floor, wall and roof) and community environment (e.g., road, green environment and street furniture). Therefore, residents' satisfaction and moving intention fluctuate through different renovation stages. Considering the low income of residents, local governments often provide a certain amount of compensation if house owners want to relocate. Although this compensation is not enough for relocation, it may influence residents' moving propensity. Similarly, as the hukou system (Chinese ID) restricts the relocation of people in China, it also may influence the moving intention of residents in historical blocks. Moreover, although Chinese generally have a higher intention to own a house, considering the constraint of low income and opportunity of good location, the moving intention from house owners and renters in these historical blocks may also be different from other urban areas. It is thus important to accumulate evidence of residential satisfaction and intentions to move house in such blocks.

Thus, this paper will examine the determinants of residential mobility in renovated Chinese historical blocks while considering whether heterogeneity exists across residents to form the mobility intention. The aim of this paper therefore is to analyse how social-demographic variables and residential satisfaction jointly influence residential moving intentions allowing for identifying both the observed and unobserved heterogeneity between residents. Consistent with the mainstream residential mobility studies that concentrated 
on the propensity to move (e.g., Earhart and Weber 1996; Kestens 2004; Liao 2004; Wu 2006; Kwon and Beamish 2013), our analysis will only consider the first stage of residential mobility, namely the mobility intention rather than real moves.

The remainder of this paper is structured as follows: the introduction section is followed by a literature review which summarises studies regarding moving intention. The next section describes the process of data collection and sample statistics. Then, the method of analysis will be presented and related results will be discussed. Based on the results, some conclusions will be drawn in the last section.

\section{Literature review}

Residential mobility has a long history of intensive study in urban planning and housing research. As mobility is significant in understanding residential preference and behaviour, the question how families move began to attract the interest of scholars since the middle 1950s. In the 1980s and 1990s, identifying variables that influence residential mobility was a popular topic of research. Even though recent years have witnessed a decrease in the analyses of residential mobility due to the shift of interest to international immigration (Coulter et al. 2013), residential mobility remains a significant topic to discuss, especially in developing countries.

Initially, Clark (1982) defined the housing, neighbourhood and accessibility as three main reasons for voluntary residential mobility. Boehm and Ihlanfeld (1986) and Lee et al. (1994) found that neighbourhood variables play an significant role in predicting mobility. Clark and Huang (2003) and Clark et al. (2006) checked the influence of neighbourhood satisfaction and stated that people who like their neighbourhood are less likely to move out. In another paper, Clark and Ledwith (2006), further addressed the trade up in housing and neighbourhood quality and found people often try to improve both during residential mobility. Kan (2007) used social capital to replace the nearby neighbourhood and found it has a negative effect on residential mobility.

Several social demographic attributes have been examined as determinants of residential mobility. Since Rossi (1955), tenure has always been included in analyses of residential mobility. It was found to have a salient effect on residential move as raised by Clark and Huang (2003), Van der Vlist et al. (2002) and Lu (2002). Baker (2002) added that private renters are more likely to move compared with other tenure groups, while the public renters have the lowest rate of mobility. Huang and Deng (2006) found that homeowners are less likely to move than renters. Besides tenure, length of stay has been subject to analyses using months as measurement scale in residential mobility studies. Varying effects are found for this attribute. McGinnis (1968) concluded that increasing length of stay will decrease the propensity to move. However, Ioannides (1987) asserted that length of stay will effect mobility jointly with tenure status. Onaka and Clark (1983) found length of stay does not have a consistent effect on mobility. Only for young couples without children, a negative effect could be observed.

Residential mobility is also considered to be the function of lifecycle events. Different events happening in an individual's life are potentially triggering the need of moving house. Rossi (1955) mentioned that life course is placed at the top of the list of reasons of residential mobility. Clark (1982) argued that life cycle is a more important determinant compared with cost, tenure, etc. Two years later, Courgeau (1985) applied a retrospective survey and found that the birth of the first child has a significant effect on increasing 
mobility rates. He also pointed out that divorce has a significant effect mainly for woman while the influence of marriage changes over time. Later Clark and Huang (2003), Feijten and van Ham (2007) and Rabe and Taylor (2010) confirmed the importance of lifecycle for couples in explaining residential mobility.

Change of job can be regarded as a lifecycle event, which potentially leads to residential mobility. Many scholars already found the positive link between job change and moving house (van Ommeren et al. 2000; Clark and Davies Withers 1999). By analysing job change, Böheim and Taylor (2002) found that unemployed people are more likely to move than employees in the UK, while Diaz-Serrano and Stoyanova (2010) argued that the influence of job change depends on the country where respondents live.

Furthermore, the relation between residential satisfaction and residential mobility attracted lots of attention in residential research. A significant influence of residential satisfaction (or dissatisfaction) on the intention to move was found by many scholars (e.g., Clark and Onaka 1983; Kearns and Parkes 2003; Oh 2003; Kwon and Beamish 2013). Speare et al. (1975) applied path analysis to study the influence of residential satisfaction on mobility. His model was confirmed by Landale and Guest (1985) and showed that satisfaction is a strong predictor of into of moving and the intention of moving will influence the real move. Earhart and Weber (1996) and Oh (2003) argued that residential satisfaction influences the intention to move house by working together with other variable like feeling of home attachment and social bonding. Diaz-Serrano and Stoyanova (2010) used panel data collected from 12 countries to find that residential satisfaction also triggers real moves. By studying the reverse causality between residential satisfaction and mobility, scholars also found that previous residential mobility will affect current residential satisfaction, in spite of the fact that those studies are based on different scales of relocation (Barcus 2004; Lu 2002; Posthumus et al. 2014).

However, in all these studies, limited researches have attempted to examine the heterogeneity issue. Even for those studies trying to identify the unobserved heterogeneity, they do not necessarily analyse the observed heterogeneity. Two mixed logit models were used by Rabe and Taylor (2010) to estimate the determinants of residential mobility with and without neighbourhood quality effects respectively. The interaction between gender and work status is found influential. Later, Dane et al. (2014) applied a mixed logit model using social-demographic information as random variables to estimate the determinants of intention to move. Observed heterogeneity is not considered in this study. Interestingly, both studies fail to identify the unobserved heterogeneity among residents for several variables. Moreover, few studies in the field of housing location choice explored the heterogeneity with mixed logit models to analyse the relationship between commuting time and house location (Rouwendal and Meijer 2001; Habib and Miller 2009; Tillema et al. 2010).

Residential mobility has also attracted an increasing number of Chinese scholars in the past decade (e.g.; Fang 2006; Li 2004; He 2015). Chinese findings are not exactly same with western results. Using data from Beijing, Fang (2006) found that in contrast to the Western literature, lower residential satisfaction causes a high intention to move house, but will not lead to more real moves. Li (2004) also found that life course, including marriage and childbirth, is not influential for residential mobility, which is different from findings in the Western world. Even for tenure status, Li (2003) and Wu (2006) found it does not necessarily drive residential mobility and migrant tenants are less likely to move. The main reason for this discrepancy may be that Chinese are facing stronger constraints and hence have less opportunity to act on their preferences and intentions. Although more constraints and opportunities are faced by residents living in Chinese historical blocks, the residential mobility studies regarding this region is still scarce. 
Table 1 Background information of eight historical blocks

\begin{tabular}{lllll}
\hline City & Block name & Areas $\left(\mathrm{km}^{2}\right)$ & Population & Location \\
\hline Chongqing & Ciqikou & 0.3 & 2710 & Ciqikou historical area \\
& Shancheng alley & 0.11 & 13,850 & Shancheng alley historical area \\
& Zhongshan 4th Road & 0.53 & Around 8000 & Zhongshan 4th Road historical area \\
Shanghai & Julu Road & 0.162 & 4616 & Nanjing Western Road historical area \\
& Shanyin Road & 0.027 & 2048 & Shanyin Road historical area \\
& Laochengxiang & 0.039 & 4381 & Laochengxiang historical area \\
& Yuyuan Road & 0.080 & Around 5000 & Yuyuan Road historical area \\
& Bugaoli & 0.065 & 2634 & Hengshan Road-Fuxing Road historical \\
& & & area \\
\hline
\end{tabular}

The detailed population cannot be provided in some blocks

The influence of the special Chinese hukou system (Chinese ID) on mobility was analysed. Hukou system declares that individuals need to have the local ID to receive local social benefits, like buying a new house with a lower price, which also restricts the residential mobility. The remaining findings regarding hukou in residential studies vary from scholars. Wu (2006) found that hukou significantly influences the real move rather than the intention to move. Huang et al. (2014) found that hukou only has effects in more developed municipalities, while He (2015) asserted that the intention to move house is generated by a combined effect of various factors. Considering its significance in Chinese society, hukou is worthy of consideration in residential mobility studies regarding historical blocks.

Few Chinese residential studies have examined the relationship between residential satisfaction and mobility. Consistent with the western studies, Fang (2006) concluded that residential satisfaction significantly influences mobility. Analysing with an inverse logic, Tao et al. (2014) found that mobility preferences influences residential satisfaction. However, the heterogeneity issue has not been included in Chinese residential studies yet.

To conclude, the residential studies systematically examining the determinants of residential mobility with an emphasis on the heterogeneity in China are limited. Although the number of studies in China has been increasing, the study of Chinese residential mobility is still at an early phase and systematic analysis of the influence of both residential satisfaction and social-demographic variables allowing for identifying the heterogeneity between residents is still lacking.

\section{Data collection}

Data used for this paper was collected from 8 historical blocks in two Chinese cites: Chongqing and Shanghai. Chongqing is located in the western part of China while Shanghai is located in the eastern part. Both cities are first-tier cities with a high GDP growth $(>7 \%)$. In order to protect their culture heritage from being engulfed in economic development, both cities established their own historical preservation areas. Considering the ratio of remaining protection areas (8 in Chongqing and 14 in Shanghai), 3 blocks from Chongqing and 5 from Shanghai were randomly selected (Table 1). All these blocks experienced different degrees of renovation. 


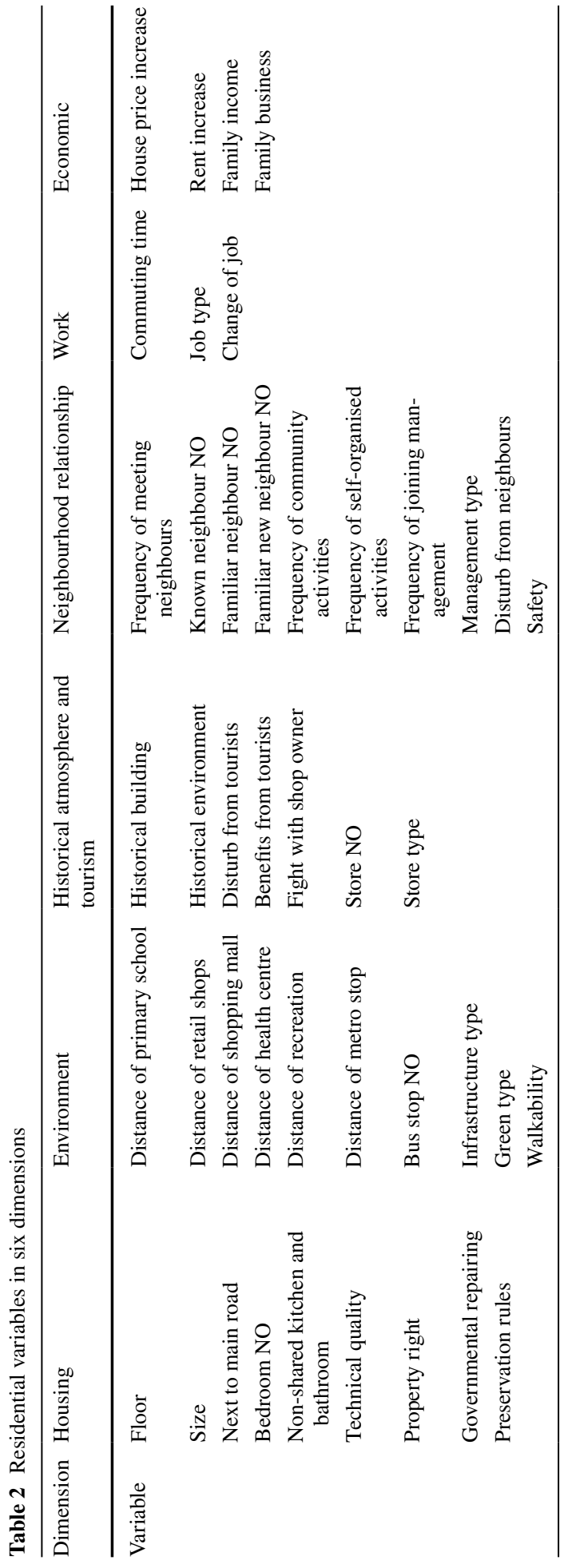


In order to better understand the relations between residential satisfaction and mobility, our questionnaire measured satisfaction based on six dimensions in line with traditional mobility research (Clark 1982; Clark and Onaka 1983), including housing, environment, historical atmosphere and tourism, neighbourhood relationship, work and economy. Every dimension contains 3-10 residential variables. Table 2 shows the residential variables in every dimension. Based on judgements of all these variables, overall satisfaction of each dimension was measured on a seven-point rating scale, ranging from 'extremely unsatisfied' to 'extremely satisfied'. As indicated by previous literature, this measure of residential satisfaction is either assumed ordinal or interval. Although this scale has the ordinal property, it is beyond a simple ordinal scale. Thus, while choosing the analysis in the present study, we assumed that the rating scale used has interval properties, following the choice taken in many prior work (e.g., Speare 1974; Molin and Timmermans 2003; Liao 2004; Diaz-Serrano and Stoyanova 2010). Finally, the intention to move was measured. After the survey, at least 3 interviews were taken in every blocks that more than 30 interviews were recorded in total.

The data was collected from April to June 2015. Respondents were selected using the spatially stratified random sampling method. 400 questionnaires were distributed and 384 valid questionnaire were completed with the help of local governments. Thus, the response rate equals $96 \%$. Table 3 shows the collective results of the mobility choice. As data was collected in a detailed way to obtain more information, some categories were merged during analysis to reduce the number of estimated parameters. Table 3 also gives descriptive information about the social demographic data. The percentage of women (51.3) is slightly higher than the percentage of men (48.7). Over half of the families does not need to support any child (56.8\%) or elderly (63.3\%). A large share of the sample (79.7\%) has a lower level of education, compared with average citizens $\left(75 \%^{1}\right) .64 .6 \%$ of the respondents have lived in the blocks for over 20 years. $52.4 \%$ of the families have a family income less than 5000 yuan (around 714 euros) and only $2.9 \%$ earns a family income over 20,000 yuan (around 2857 euros) per month. As for the stage of renovation, 2 blocks (25.3\% of respondents) are still at the early stage of renovation and only underwent a few rounds of small renovations before and might encounter larger scale renovation soon; very few natives have moved out until now. 4 blocks (51.6\% of the respondents) are during the middle stage of renovation, which means they have already experienced at least one around of large scale renovation. There are no immediate plans of further renovation; nothing will change much in the short run, but these blocks still have the potential of renewal again in the future. Another 2 blocks (23.2\% of respondents) are already at a late stage of renovation. They have experienced several rounds of renovation and will not have huge scale renovation soon. A large percentage of local residents has already been replaced. Most respondents have the hukou from the same city (89.1\%) while very few have it from other cities or villages (10.9\%). 57.3\% of the families rent a house while the rest owns the house or share properties with the government. Figure 1 displays the distribution of age showing that residents in historical blocks tend to be relatively old with $43.8 \%$ of the respondents being 60 or over and their average age is 55 years old.

The statistic description of residential satisfaction is shown in Table 4, on average, residents have the highest satisfaction about the neighbourhood bonding as expected, which is followed by working satisfaction. The lowest residential satisfaction is found in housing dimension, which is reasonable as houses in those historical blocks are generally in a worse situation compared with houses in other urban areas. Data regarding all the dimensional satisfaction is found to have some variance.

\footnotetext{
${ }^{1}$ http://www.stats.gov.cn/tjsj/pcsj/rkpc/6rp/indexce.htm.
} 


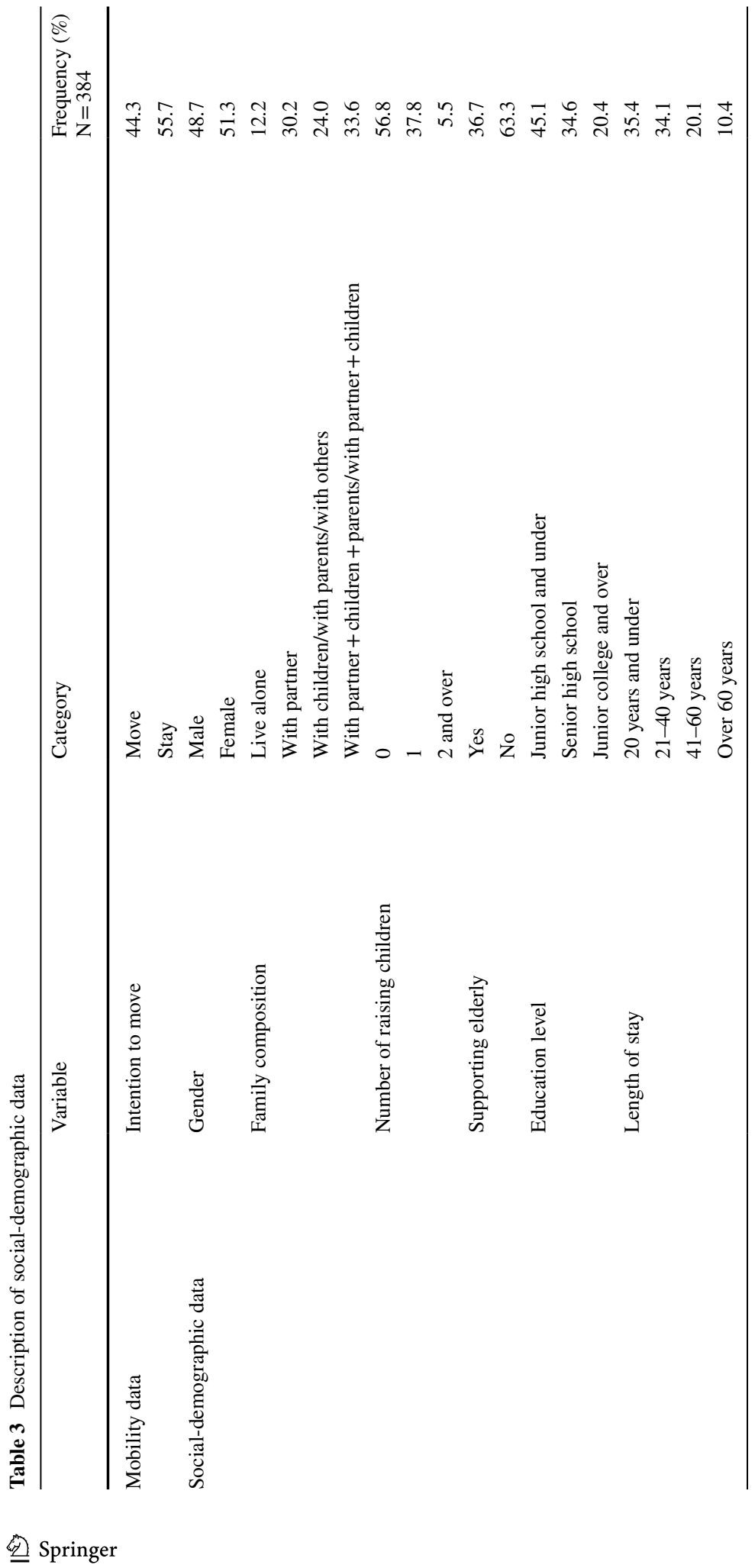




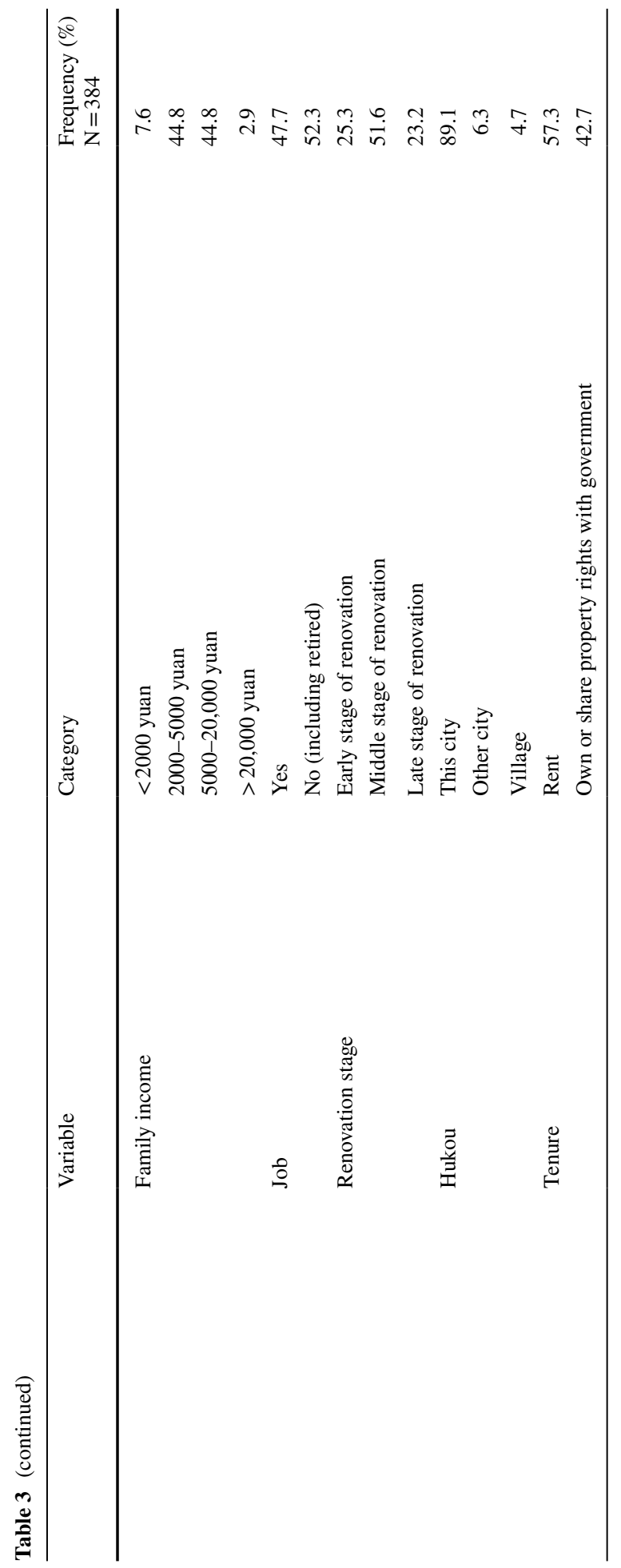




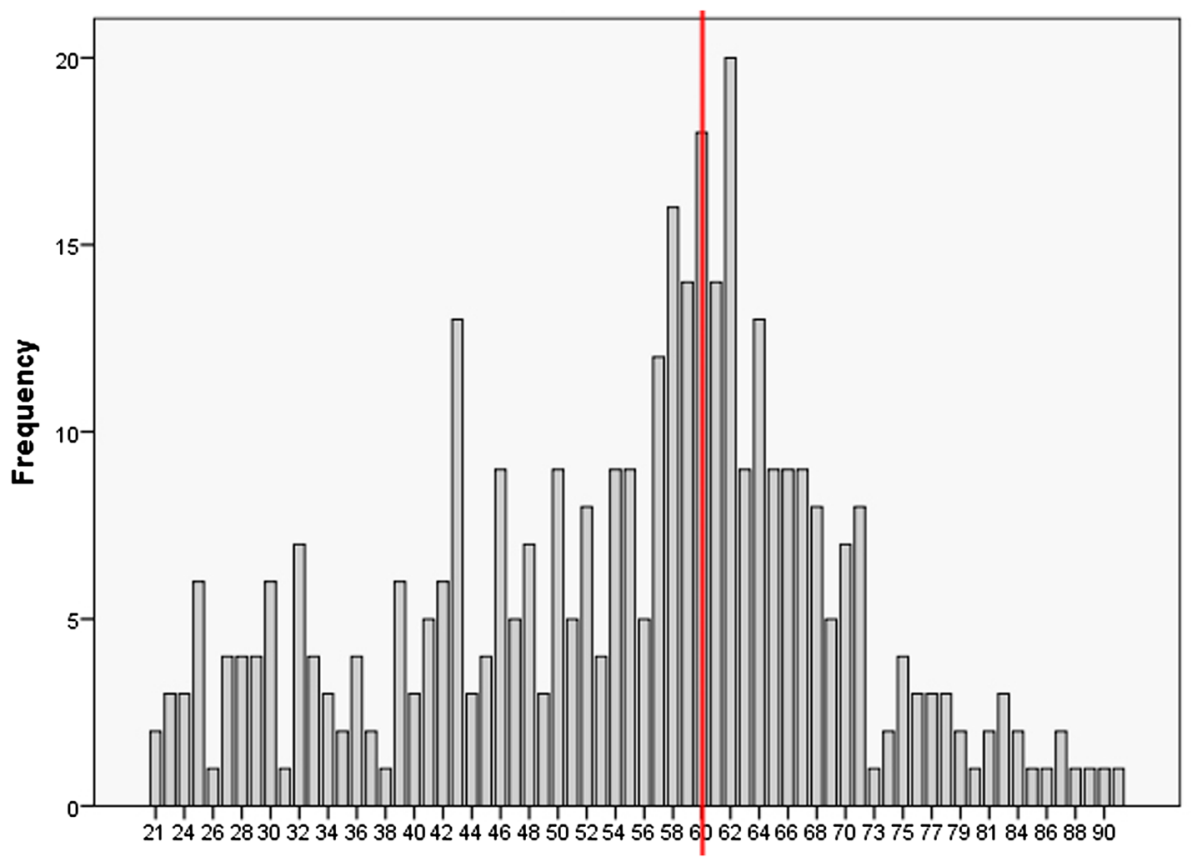

Fig. 1 Frequency distribution of age

Table 4 Description of dimensional satisfaction

\begin{tabular}{lllllll}
\hline $\begin{array}{l}\text { Satisfac- } \\
\text { tion dimen- } \\
\text { sion }\end{array}$ & $\begin{array}{l}\text { Housing } \\
\text { satisfac- } \\
\text { tion }\end{array}$ & $\begin{array}{l}\text { Environmen- } \\
\text { tal satisfac- } \\
\text { tion }\end{array}$ & $\begin{array}{l}\text { Historical } \\
\text { atmosphere and } \\
\text { tourism satisfac- } \\
\text { tion }\end{array}$ & $\begin{array}{l}\text { Neighbourhood } \\
\text { relationship } \\
\text { satisfaction }\end{array}$ & $\begin{array}{l}\text { Work satisfac- } \\
\text { tion }\end{array}$ & $\begin{array}{l}\text { Economic } \\
\text { satisfac- } \\
\text { tion }\end{array}$ \\
\hline Mean & 3.910 & 4.380 & 4.376 & 4.906 & 4.640 & 4.090 \\
SD & 1.238 & 1.087 & 0.848 & 0.769 & 0.840 & 0.928 \\
\hline
\end{tabular}

\section{Method}

As the aim of this paper is to examine the determinants of intention to move considering the heterogeneity in renovated Chinese historical blocks, the influence of social-demographic variables, residential satisfaction and heterogeneity will be analysed stepwise. Four steps in the analysis will be taken. To understand the influence of general social-demographics and background attributes regarding the context of China and historical blocks, a multinomial logit model (MNL) will be adopted first. Then another two MNL models will be adopted to examine the influence of residential satisfaction and observed heterogeneity, respectively. Considering that residents from the blocks at different renovation stage may have different moving intention despite the same residential satisfaction, the observed heterogeneity will be captured by investigating the joint effect of renovation stages and satisfaction on moving propensity. In the last step, a mixed logit model will be estimated to explore the unobserved heterogeneity between residents. 
Mixed logit models are typically used to capture the heterogeneous behaviour through the assumption of random parameters. Different from standard multinomial logit model that estimates a fixed parameter for all individuals, the mixed logit model estimates the mean and standard deviation of random parameters according to the assumed statistical distribution. Considering that people are different, so the parameter estimates may vary over individuals, the use of mixed logit can explore the taste variation between people. Also, a generalised mixed logit model is not subject to the independence of irrelevant alternatives (IIA) restrictions on the choice probabilities.

For exploring the unobserved heterogeneity between residents, the random parameters will be specified in the mixed logit model, then the standard deviation of the specified random parameter will be analysed so that unobserved heterogeneity between individuals can be examined. As different renovation stages changed the living environment for residents, they are assumed to most affect residents' thoughts about housing individually and used as random parameters to estimate the taste variation between residents in renovated historical blocks. All the categorical attributes were effect coded and $n-1$ variables (every attribute has $n$ categories) were involved in the estimation.

Although lifecycle is commonly considered to be a significant determinant in residential mobility, they are excluded in this analysis as it is hard to collect data associated with lifecycle.

\section{Results and discussion}

The results of the three multinomial logit and one mixed logit model are listed in Table 5. As the table shows, the Rho squared increases after adding variables every time. Compared with the multinomial logit model (Model 3), the mixed logit model (Model 4) resulted in only a slightly better fit (Rho squared $=0.237$ ). It suggests that the sample of respondents is rather homogeneous and that much of the taste variation is already captured by the observed socio-demographics, although as we will see soon, even most of the socio-demographic variables are not significant. Even though the sign of some social-demographic variables have been changed after adding residential satisfaction variables, by and large, the estimates of models are consistent. The change of sign may because of the correlations between these two groups of variables.

An examination of Table 5 shows that the estimated constant in all four models is positive and significant. It indicates that residents in renovated historical blocks on average have the preference of intention to move. Results of Model 2 indicate that age, renovation stage, tenure, housing satisfaction and satisfaction with the environment are statistically significant. Age significantly impacts the mobility intention (-0.040). Its negative sign shows that the older the residents, the lower the intention to move house. For variables regarding the background context, renting a house is found to influence moving intention significantly $(-0.356)$. The negative sign indicates that renters have a lower intention to move compared with house owners. It is reasonable considering that renters may not afford to buy a house and move out, while house owners can receive a high profit by selling or renting their houses due to the central location of these historical blocks and get some compensation from the government at the same time. The early stage of renovation is found to be influential variable for residential mobility (0.6224). Compared with people from other renovation stages, residents living in historical blocks during middle renovation stage are less likely to move. As the renovation continues, the intention to move increases at the early and late stages. This may suggest that renovation from government more or 
Table 5 The summarised results of four models

\begin{tabular}{|c|c|c|c|c|}
\hline & Model 1 & Model 2 & Model 3 & Model 4 \\
\hline R-squared & 0.108 & 0.214 & 0.230 & 0.237 \\
\hline \multicolumn{5}{|l|}{ Social-demographic variables } \\
\hline Constant & $2.150 * * *$ & $6.661 * * *$ & $7.921 * * *$ & $8.129 * * *$ \\
\hline Job or not & $-0.303^{*}$ & -0.177 & -0.118 & -0.124 \\
\hline Gender & -0.071 & 0.064 & 0.054 & 0.057 \\
\hline Age & $-0.043 * * *$ & $-0.040 * * *$ & $-0.036 * *$ & $-0.038 * *$ \\
\hline Family composition 1 (live alone) & -0.018 & -0.075 & -0.010 & -0.002 \\
\hline $\begin{array}{l}\text { Family composition } 2 \text { (live with } \\
\text { partner) }\end{array}$ & 0.012 & 0.003 & 0.037 & 0.036 \\
\hline $\begin{array}{l}\text { Family composition } 3 \text { (live with } \\
\text { children or parents or other } \\
\text { relatives) }\end{array}$ & -0.195 & -0.093 & -0.131 & -0.132 \\
\hline Number of raising children 1 & -0.144 & 0.030 & 0.065 & 0.053 \\
\hline Number of raising children 2 & -0.090 & -0.126 & -0.054 & -0.055 \\
\hline Supporting the eldly & 0.094 & 0.030 & 0.047 & 0.045 \\
\hline Education level 1 (low) & 0.066 & 0.122 & 0.168 & 0.171 \\
\hline Education level 2 (middle) & 0.170 & 0.054 & 0.041 & 0.043 \\
\hline Length of stay 1 & -0.185 & -0.161 & -0.106 & -0.103 \\
\hline Length of stay 2 & 0.057 & 0.050 & 0.097 & 0.103 \\
\hline Length of stay 3 & 0.074 & 0.050 & 0.054 & 0.052 \\
\hline Family income 1 (<2000 yuan) & 0.130 & 0.191 & 0.343 & 0.353 \\
\hline $\begin{array}{l}\text { Family income } 2(2000-5000 \\
\text { yuan) }\end{array}$ & -0.129 & -0.169 & -0.276 & -0.277 \\
\hline $\begin{array}{l}\text { Family income } 3 \text { (5000-20,000 } \\
\text { yuan) }\end{array}$ & 0.114 & 0.098 & 0.069 & 0.070 \\
\hline Early renovation stage & $0.889 * * *$ & $0.622 * * *$ & 2.276 & 2.131 \\
\hline Middle renovation stage & $-0.436 * * *$ & -0.263 & $-3.007 *$ & $-3.064^{*}$ \\
\hline Hukou 1 (this city) & 0.283 & -0.018 & -0.027 & -0.009 \\
\hline Hukou 2 (other city) & -0.511 & -0.546 & -0.493 & -0.525 \\
\hline Rent or not & -0.102 & $-0.356^{* *}$ & $-0.317 * *$ & $-0.327 * *$ \\
\hline \multicolumn{5}{|l|}{ Residential satisfaction variables } \\
\hline Satisfaction of housing & & $-0.611 * * *$ & $-0.656^{* * *}$ & $-0.676^{* * *}$ \\
\hline Satisfaction of environment & & $-0.325^{* *}$ & $-0.442 * *$ & $-0.455^{* *}$ \\
\hline $\begin{array}{l}\text { Satisfaction of historical atmos- } \\
\text { phere and tourism }\end{array}$ & & 0.036 & 0.054 & 0.049 \\
\hline Satisfaction of neighbourhood & & -0.006 & -0.218 & -0.214 \\
\hline Satisfaction of job & & -0.192 & -0.198 & -0.202 \\
\hline Satisfaction of economy & & 0.005 & 0.054 & 0.056 \\
\hline \multicolumn{5}{|c|}{ Interaction between renovation stage and satisfaction } \\
\hline $\begin{array}{l}\text { Early renovation stage } \times \text { satisfac- } \\
\text { tion of housing }\end{array}$ & & & -0.098 & -0.078 \\
\hline $\begin{array}{l}\text { Early renovation stage } \times \text { satisfac- } \\
\text { tion of environment }\end{array}$ & & & -0.165 & -0.154 \\
\hline $\begin{array}{l}\text { Early renovation stage } \times \text { satisfac- } \\
\text { tion of historical atmosphere and } \\
\text { tourism }\end{array}$ & & & 0.174 & 0.179 \\
\hline
\end{tabular}


Table 5 (continued)

\begin{tabular}{|c|c|c|c|c|}
\hline & Model 1 & Model 2 & Model 3 & Model 4 \\
\hline $\begin{array}{l}\text { Early renovation stage } \times \text { satisfac- } \\
\text { tion of neighbourhood }\end{array}$ & & & $-0.572^{*}$ & $-0.574 *$ \\
\hline $\begin{array}{l}\text { Early renovation stage } \times \text { satisfac- } \\
\text { tion of economy }\end{array}$ & & & 0.358 & 0.362 \\
\hline $\begin{array}{l}\text { Middle renovation stage } \times \text { satisfac- } \\
\text { tion of housing }\end{array}$ & & & 0.112 & 0.106 \\
\hline $\begin{array}{l}\text { Middle renovation stage } \times \text { satisfac- } \\
\text { tion of environment }\end{array}$ & & & 0.103 & 0.103 \\
\hline $\begin{array}{l}\text { Middle renovation stage } \times \text { satisfac- } \\
\text { tion of historical atmosphere and } \\
\text { tourism }\end{array}$ & & & 0.085 & 0.099 \\
\hline $\begin{array}{l}\text { Middle renovation stage } \times \text { satisfac- } \\
\text { tion of neighbourhood }\end{array}$ & & & 0.397 & 0.402 \\
\hline $\begin{array}{l}\text { Middle renovation stage } \times \text { satisfac- } \\
\text { tion of economy }\end{array}$ & & & -0.118 & -0.122 \\
\hline \multicolumn{5}{|l|}{ Random parameter } \\
\hline Early renovation stage & & & & 0.002 \\
\hline Middle renovation stage & & & & 0.490 \\
\hline
\end{tabular}

$* * * P<0.01 ; * * P<0.05 ; * P<0.1$

less changed both the tangible and intangible living environment. This quantitative result was confirmed during our qualitative interviews in which residents mentioned that after a few rounds of renovation, they do find their living conditions improved. So they were happy about their houses and less interested in moving out. However, because the historical buildings were partly made from wood and always need repair, a few rounds of small scale renovation cannot stop the trend of deterioration. Therefore, after some time, in spite of more rounds of renovation, residents were more inclined to move as they think the renovation cannot solve the fundamental problems, such as housing structure and house size. Although hukou is found not influential on moving propensity, the coefficient still indicates that residents holding hukou of the current city and village have higher moving intention compared with those holding hukou of other cities. This finding is confirmed in the interviews that residents holding hukou from other cities are more reluctant to move as they have less expectations of change.

Regarding other social-demographic variables, although the results suggest that they are statistically insignificant, some trends can still be observed. The negative sign of having a job indicates that people who have a job have a lower intention to move compared with those retired or having no job. It might be because people with a job are more stable than those without a job. Some respondents mentioned in the interviews that they cannot move because their work places are nearby and it would be inconvenient for their commuting if they relocate. Gender positively influences residential mobility, which indicates that males have a higher intention to move compared with females. The changing signs of family composition indicate that residents who live alone and live with children or parents or other relatives are less interested in moving compared with residents living with a partner or extended family. The result is consistent with researches focusing on lifecycle that marriage will lead to higher moving intention (Clark and Huang 2003; Feijten and van Ham 2007; Rabe and Taylor 2010). Similarly, supporting more elderly at home will also 
induce a higher mobility intention relative to the families supporting less elderly. In terms of length of stay, residents who live less than 20 years and longer than 60 years in historical blocks have a lower intention to move than other residents. Higher education level also shows a negative effect on the intention to move in the sense that residents with a higher education level have a lower inclination to relocate than residents with lower education levels. For families with the lowest income, they are more interested in moving compared to the families with higher income, which might be because some respondents with low family income mentioned that they intend to get high profits from selling houses and the compensation from government during relocation to improve their economic situation.

As for the various satisfaction variables, Model 2 shows that housing satisfaction contributes significantly to the intention to move house $(-0.611)$. Its negative impact suggests that lower housing satisfaction leads to a higher intention to move, which is consistent with previous research about other urban area (e.g., Kearns and Parkes 2003; Oh 2003). Housing satisfaction is also the most important variable influencing residential mobility compared with other satisfaction variables. Following housing satisfaction, satisfaction with the environment also significantly influences the mobility intention $(-0.325)$. This negative coefficient also indicates that the higher environmental satisfaction, the lower the propensity to move. Similarly, neighbourhood satisfaction and job satisfaction have a negative sign, showing that the intention to move house decreases with increasing satisfaction with neighbourhoods and jobs. Historical and economic satisfaction show an unexpected positive sign; however none of them are statistically significant. In this context, it should also be emphasised that all satisfaction variables are intercorrelated. If we examine the single correlations, results indicate that historical satisfaction and economic satisfaction are negatively correlated with the intention to move house as we would assume. Thus, the negative signs in the logit model is likely due to the correlation among the satisfaction variables.

After adding the interaction between renovation stage and satisfaction variables, the observed heterogeneity is captured in Model 3. The estimates suggest that the neighbourhood satisfaction significantly interacts with several renovation stages. Specifically, with same neighbourhood satisfaction, residents living in blocks of early renovation $(-0.574)$ have a lower inclination to move compared with those from blocks of later renovation (0.402), which is different from results of renovation stage. A likely explanation is that social bonding was destroyed during renovation as more neighbours were replaced. The same trend is found in interaction with environmental satisfaction. Similarly, lower housing satisfaction is found to reduce the intention to move in early renovation stage. As historical and economic satisfaction exhibit unexpected signs and are statistically insignificant, their interaction effects will not be interpreted.

Although renovation stages are assumed to show taste variation, the standard deviation of these random parameters are statistically insignificant in Model 4. It means residents living in historical blocks at different renovation stages do not exhibit significant differences in their propensity to move house.

\section{Conclusions}

The aim of this paper is to systematically understand residential satisfaction and socialdemographic characteristics as determinants impacting residential mobility considering the existence of observed and unobserved heterogeneity between residents. The results of multinomial logit and mixed logit models indicate that residential satisfaction is an important 
impactor of residential mobility in renovated Chinese historical blocks, which is consistent with previous researches (e.g., Kwon and Beamish 2013). Among the social-demographic attributes, age, renovation stage and tenure are found to significantly influence mobility intention. Renters are found with a lower intention to move, which is similar to findings from other urban areas (Li 2003; Wu 2006), but maybe due to different reasons. Although holding the hukou of other city may reduce the propensity to move, the Chinese ID does not necessarily restrict the moving intention of residents living in historical blocks. Moreover, the observed heterogeneity was captured, while the unobserved heterogeneity regarding renovation stages was not identified.

The estimates of MNL models indicate that the social-demographic characteristics like length of stay is found not affect mobility consistently, which is in line with Onaka and Clark (1983), but because of distinct reasons. Another variable, age, negatively influences the intention to move, which confirms earlier findings for other urban areas (Earhart and Weber 1996; Clark and Huang 2003). Consistent with previous Western studies for other urban areas (Clark and Huang 2003; Feijten and van Ham 2007), people living with a partner or extended family are more likely to move compared with those living alone or with few relatives, which is, however, inconsistent with finding from other urban areas in Shanghai (Li and Song 2009).

Most satisfaction variables have a negative impact on residential mobility. It means when certain dimension of satisfaction increases, the intention to move decreases. Housing satisfaction is found to be the most influential variable compared with other satisfaction variables. The study also revealed that the joint effects of renovation stage and neighbourhood satisfaction are influential on the propensity to move. For residents having the same neighbourhood satisfaction, those who live in early renovation stage are less likely to have moving intention, which is reasonable considering that increasing number of local residents are replaced as the renovation continues. However, there is no variation in residents' taste regarding renovation stage. Residents living in blocks of the same renovation stages have similar preference contributing to the mobility intention.

Results of this paper can provide renovation suggestions for the local authorities. First, as the elderly is found to have lower moving intention, the aging population in these blocks will increase over years. Providing more convenient walking environment and facilities (e.g., sports and greens) for the elderly in those blocks should be considered in future renovations. Second, more renovation support regarding housing should be provided by the local government. For instance, the repair support of infrastructure and material renewal. It is not only because housing itself is considered most important for residents living in historical blocks, but also because the house condition in historical blocks is worse than other urban areas. Third, as the interaction between renovation stage and neighbourhood satisfaction is significant and increasing number of local residents move out during the renovation process, how to improve the renovation to create better living environment and reduce deterioration of social fabric is worthy consideration by policy makers.

Although this study provides some insights into the influence of social-demographic characteristics and residential satisfaction on intention to move, further investigation about the effect of more detailed attributes behind satisfaction variables on residential mobility still remains for further studies.

Open Access This article is distributed under the terms of the Creative Commons Attribution 4.0 International License (http://creativecommons.org/licenses/by/4.0/), which permits unrestricted use, distribution, and reproduction in any medium, provided you give appropriate credit to the original author(s) and the source, provide a link to the Creative Commons license, and indicate if changes were made. 


\section{References}

Baker, E. (2002). Public housing tenant relocation: Residential mobility, satisfaction, and the development of a tenant's spatial decision support system. Adelaide: The University of Adelaide.

Barcus, H. (2004). Urban-rural migration in the USA: An analysis of residential satisfaction. Regional Studies, 38(6), 643-657. https://doi.org/10.1080/003434042000240950.

Boehm, T. P., \& Ihlanfeld, K. R. (1986). Residential mobility and neighborhood quality. Journal of Regional Science, 26(2), 411-424. https://doi.org/10.1111/j.1467-9787.1986.tb00828.x.

Böheim, R., \& Taylor, M. P. (2002). Tied down or room to move? Investigating the relationships between housing tenure, employment status and residential mobility in Britain. Scottish Journal of Political Economy, 49(4), 369-392. https://doi.org/10.1111/1467-9485.00237.

Clark, W. A. V. (1982). Recent research on migration and mobility: A review and interpretation. Progress in Planning, 18(PART 1), 1-56. https://doi.org/10.1016/0305-9006(82)90002-2.

Clark, W. A. V., \& Coulter, R. (2015). Who wants to move? The role of neighbourhood change. Environment and Planning A, 47(12), 2683-2709. https://doi.org/10.1177/0308518X15615367.

Clark, W. A. V., \& Davies Withers, S. (1999). Changing jobs and changing houses: mobility outcomes of employment transitions. Journal of Regional Science, 24(3), 273-274. https://doi.org/10.1111/00224146.00154 .

Clark, W., Deurloo, M., \& Dieleman, F. (2006). Residential mobility and neighbourhood outcomes. Housing Studies, 21(3), 323-342. https://doi.org/10.1080/02673030600585946.

Clark, W. A. V., \& Huang, Y. (2003). The life course and residential mobility in British housing markets. Environment and Planning A, 35(2), 323-339. https://doi.org/10.1068/a3542.

Clark, W. A. V., \& Ledwith, V. (2006). Mobility, housing stress, and neighborhood contexts: Evidence from Los Angeles. Environment and Planning A, 38(6), 1077-1093. https://doi.org/10.1068/a37254.

Clark, W. A. V., \& Onaka, J. (1983). Life cycle and housing adjustment as explanations of residential mobility. Urban Studies, 20(1), 47-57. https://doi.org/10.1080/713703176.

Coulter, R., Van Ham, M., \& Findlay, A. (2013). New directions for residential mobility research: Linking lives through time and space. IZA Discussion Paper No. 7525.

Courgeau, D. (1985). Interaction between saptial mobility, family and career life-cyle: A French survey. European Sociological Review, 1(2), 139-162.

Dane, G. Z., Griglon, A. B., Rasouli, S., \& Timmermans, H. (2014). Determinants of residential mobility intentions: A mixed binary logit model. In The 19th international conference of Hong Kong society for transportation studies (Vol. 12, pp. 1-8). Hong Kong. http://doi.org/10.1017/CBO97 81107415324.004.

Diaz-Serrano, L., \& Stoyanova, A. P. (2010). Mobility and housing satisfaction: An empirical analysis For 12 EU countries. Journal of Economic Geography, 10(5), 661-683. https://doi.org/10.1093/jeg/ $1 \mathrm{bp} 045$.

Earhart, C. C., \& Weber, M. J. (1996). Attachment-to-home: A contributing factor to models of residential mobility intentions. Family and Consumer Sciences Research Journal, 24(4), 422-437. https:// doi.org/10.1177/1077727X960244007.

Fang, Y. (2006). Residential satisfaction, moving intention and moving behaviours: A study of redeveloped neighbourhoods in inner-city Beijing. Housing Studies, 21(2), 671-694. https://doi. org/10.1080/02673030600807217.

Feijten, P., \& van Ham, M. (2007). Residential mobility and migration of the divorced and separated. Demographic Research, 17, 623-654. https://doi.org/10.4054/DemRes.2007.17.21.

Habib, M. A., \& Miller, E. J. (2009). Reference-dependent residential location choice model within a relocation context. Transportation Research Record, 2133(1), 92-99. https://doi. org/10.3141/2133-10.

He, S. (2015). Understanding residential relocation satisfaction and intention in Guangzhou, China (April 2015).

Huang, Y., \& Deng, F. F. (2006). Residential mobility in Chinese cities: A longitudinal analysis. Housing Studies, 21(5), 625-652. https://doi.org/10.1080/02673030600807084.

Huang, X., Dijst, M., van Weesep, J., \& Zou, N. (2014). Residential mobility in China: Home ownership among rural-urban migrants after reform of the hukou registration system. Journal of Housing and the Built Environment, 29(4), 615-636. https://doi.org/10.1007/s10901-013-9370-5.

Ioannides, Y. M. (1987). Residential mobility and housing tenure choice. Regional Science and Urban Economics, 17(2), 265-287. https://doi.org/10.1016/0166-0462(87)90050-0. 
Kan, K. (2007). Residential mobility and social capital. Journal of Urban Economics, 61(3), 436-457. https://doi.org/10.1016/j.jue.2006.07.005.

Kearns, A., \& Parkes, A. (2003). Living in and leaving poor neighbourhood conditions in England. Housing Studies, 18(6), 827-851. https://doi.org/10.1080/0267303032000135456.

Kestens, Y. (2004). Land use, accessibility and household profile: Effects on residential choice and property values. Québec: Laval University.

Kim, H., Woosnam, K. M., Marcouiller, D. W., \& Aleshinloye, K. D. (2015). Residential mobility, urban preference, and human settlement: A South Korean case study. Habitat International, 49, 497-507. https://doi.org/10.1016/j.habitatint.2015.07.003.

Kwon, H. J., \& Beamish, J. O. (2013). Older adults in multifamily housing: Residential satisfaction and intention to move. Family and Consumer Sciences Research Journal, 42(1), 40-54. https://doi. org/10.1111/fcsr. 12037 .

Landale, N. S., \& Guest, A. M. (1985). Constraints, satisfaction and residential mobility: Speare's model reconsidered. Demography, 22(2), 199-222.

Lee, B. A., Oropesa, R. S., \& Kanan, J. W. (1994). Neighborhood context and residential mobility. Demography, 31(2), 249-270. https://doi.org/10.2307/2061885.

Li, S. (2003). Housing tenure and residential mobility in urban China: A study of commodity housing development in Beijing and Guangzhou. Urban Affairs Review, 38(4), 510-534. https://doi. org/10.1177/1078087402250360.

Li, S. (2004). Life course and residential mobility in Beijing, China. Environment and Planning A, 36(1), 27-43. https://doi.org/10.1068/a35243.

Li, S., \& Song, Y. (2009). Redevelopment, displacement, housing conditions, and residential satisfaction: A study of Shanghai. Environment and Planning A, 41(5), 1090-1108. https://doi. org/10.1068/a4168.

Liao, P. (2004). Emotional attachment, residential satisfaction, and mobility propensity. Journal of Population Studies, 28, 49-79.

Lu, M. (2002). Are pastures greener? Residential consequences of migration. International Journal of Population Geography, 8(3), 201-216. https://doi.org/10.1002/ijpg.244.

McGinnis, R. (1968). A stochastic model of social mobility. American Sociological Review, 33(5), 712-722.

Molin, E. J. E., \& Timmermans, H. J. P. (2003). Testing hierarchical information integration theory: The causal structure of household residential satisfaction. Environment and Planning A, 35(1), 43-58. https://doi.org/10.1068/a3416.

Oh, J. (2003). Social bonds and the migration intentions of elderly urban residents: The mediating effect of residential satisfaction. Population Research and Policy Review, 22(2), 127-146.

Onaka, J. L., \& Clark, W. A. V. (1983). A disaggregate model of residential mobility and housing choice. Geographical Analysis, 15(4), 287-304. https://doi.org/10.1111/j.1538-4632.1983.tb00788.x.

Posthumus, H., Bolt, G., \& van Kempen, R. (2014). Victims or victors? The effects of forced relocations on housing satisfaction in Dutch cities. Journal of Urban Affairs, 36(1), 13-32. https://doi.org/10.1111/ juaf.12011.

Rabe, B., \& Taylor, M. (2010). Residential mobility, quality of neighbourhood and life course events. Journal of the Royal Statistical Society. Series A: Statistics in Society, 173(3), 531-555. https://doi. org/10.1111/j.1467-985X.2009.00626.x.

Ren, H., \& Folmer, H. (2017). Determinants of residential satisfaction in urban China: A multi-group structural equation analysis. Urban Studies, 54(6), 1-19. https://doi.org/10.1177/0042098015627112.

Rossi, P. H. (1955). Why families move. Glenco, IL: The Free Press.

Rouwendal, J., \& Meijer, E. (2001). Preferences for housing, jobs, and commuting: A mixed logit analysis. Journal of Regional Science, 41(3), 475-505. https://doi.org/10.1111/0022-4146.00227.

Speare, J. A. (1974). Residential satisfaction as an intervening variable in residential mobility. Demography, 11(2), 173-188. https://doi.org/10.2307/2060556.

Speare, J. A., Goldstein, S., \& Frey, W. H. (1975). Residential mobility, migration, and metropolitan change. Philadelphia: Ballinger Pub. Co!.

Tao, L., Wong, F. K. W., \& Hui, E. C. M. (2014). Residential satisfaction of migrant workers in China: A case study of Shenzhen. Habitat International, 42, 193-202. https://doi.org/10.1016/j.habitatint .2013.12.006.

Tillema, T., van Wee, B., \& Ettema, D. (2010). The influence of (toll-related) travel costs in residential location decisions of households: A stated choice approach. Transportation Research Part A: Policy and Practice, 44(10), 785-796. https://doi.org/10.1016/j.tra.2010.07.009.

Van der Vlist, A. J., Gorter, C., Nijkamp, P., \& Rietveld, P. (2002). Residential mobility and local housingmarket differences. Environment and Planning A, 34(7), 1147-1164. https://doi.org/10.1068/a34176. 
van Ommeren, J., Rietveld, P., \& Nijkamp, P. (2000). Job mobility, residential mobility and commuting: A theoretical analysis using search theory. The Annals of Regional Science, 34(2), 213-232. https://doi. org/10.1007/s001689900004.

Wu, W. (2006). Migrant intra-urban residential mobility in urban China. Housing Studies, 21(5), 745-765. https://doi.org/10.1080/02673030600807506. 